\section{What is this thing called injury prevention?}

\author{
Roderick J McClure
}

I ask this, not as a rhetorical question, but a sincere one. ${ }^{1}$ There is a distinguished history of the self-conscious search for an identity statement for 'injury'. A codified set of descriptors from WHO's International Statistical Classification of Disease and Related Health Problems (ICD) is generally used as injury's manifestational definition. $^{2} 3$ Several common, but not universal, definitions are available to categorise the necessary additional dimension of severity. ${ }^{4} 5$ Haddon's seminal work explaining the role of energy as agent in an epidemiological model of injury causation is now concreted into injury's conceptual, aetiological definition. ${ }^{67}$ Has there been a similar search for the identity of 'injury prevention'?

Using language that is essentially manifestational, injury prevention is frequently described as the process of intervening in the causation of injury in a way that reduces the frequency (or severity) of injuries in an individual or population. ${ }^{8}$ This definition does not yet codify the nature of the injury prevention field with the same clarity with which the ICD captures the nature of injury.

Here is the challenge for the Journal. What answers would we get, if we asked a random group of the Journal's authors, whether the range of manuscripts we publish in Injury Prevention pegs out the territory that covers the field's full potential? If not, why not, and what topics are missing? What answers would we get if we asked those same questions of urban designers, industrial engineers, data scientists and community psychologists? What answers would we get if we asked researchers from core disciplines beyond those usually evident in the Journal, to identify new and innovative methodologies from their fields that could be applied

Correspondence to Dr Roderick J McClure, School of Rural Medicine, University of New England, Armidale, NSW 2351, Australia; rmcclure@une.edu.au to the problems faced by injury prevention researchers?

So why does this all matter? What is my point? Our understanding of injury prevention appears to be insufficient to support a formulation of its conceptual, aetiological definition. As explained by Langley when arguing for a clear definition of injury itself, without a comprehensive definition of the subject of interest, we cannot expect to study it in a way that moves forward with the clarity and productivity required. $^{7}$

There is a counter argument; that is, that injury prevention is not a field in its own right but simply the term for a set of applied activities, and that each activity is supported by its own disciplinary rationale. This argument posits injury prevention as a synthetic construct of little real use, other than as an umbrella concept to support a taxonomy. Road safety, violence prevention, drowning prevention, falls prevention, and opioid misuse prevention, have different constituencies, causal pathways, contexts, funding and responsible agencies. Architects of the social institutions whose policies and practices support safer societies reduce injury almost as a by-product rather than the intended outcome of their role. These prevention activities are fragmented, and sometimes unconscious, but, in situ, are relevant and practical and definable and demonstrably effective. Arguably, a higher level, synthetic construct that is injury prevention adds nothing to each activity's success.

So which of the above described arguments is the most useful? Surely the former. Identifiable and practical the set of fragmented activities that reduce the frequency of injury may be, but standing alone, they are neither self-sustaining nor self-improving. Unifying theorems and self-conscious exploration of empirically observed phenomena have long been the stalwart of scientific development. The underlying theoretical concepts are what provide the foundations of knowledge for a field, and in turn support the field's growth and application. ${ }^{1}$ Without an explicit understanding of the common conceptual underpinnings of injury prevention in all its contexts, there is no platform from which to drive change.

And the challenge for the Journal? We editors, authors and readers all have the opportunity to deliver our best answer. ${ }^{9}$ In doing so, we can all continue to develop the conceptual, aetiological basis of injury prevention and implicitly define its meaning in terms of the depth and breadth of the material Injury Prevention publishes.

\section{Competing interests None declared.}

Patient consent Not required.

Provenance and peer review Commissioned; internally peer reviewed.

(C) Article author(s) (or their employer(s) unless otherwise stated in the text of the article) 2018. All rights reserved. No commercial use is permitted unless otherwise expressly granted.

\section{Check for updates}

To cite McClure RJ. Inj Prev 2018;24:177.

Inj Prev 2018;24:177.

doi:10.1136/injuryprev-2018-042838

\section{REFERENCES}

1 Chalmers AF. What is this thing called science? Open University Press, 1999.

2 World Health Organisation. International statistical classification of diseases and related health problems, 10th revision (ICD-10). Geneva: WHO, 1992.

3 Hedegaard H, Johnson RL, Warner M, et al. Proposed framework for presenting injury data using the International Classification of Diseases, Tenth Revision, Clinical Modification (ICD-10-CM) diagnosis codes. Natl Health Stat Report 2016;16:1-20.

4 Langley J. Severity of injury can be assessed on a number of dimensions. Inj Prev 2014;20:218.

5 Schluter PJ, Nathens A, Neal ML, et al. Trauma and Injury Severity Score (TRISS) coefficients 2009 revision. J Trauma 2010;68:761-70.

6 Haddon W. On the escape of tigers: an ecologic note. Am J Public Health Nations Health 1970;60:2229-34.

7 Langley J, Brenner R. What is an injury? Inj Prev 2004;10:69-71.

8 Centers for Disease Control and Prevention, National Center for Injury Prevention and Control. Our approach. https://www.cdc.gov/injury/about/approach.html.

9 McClure RJ. Injury Prevention: where to from here? Inj Prev 2018;24:1. 